\title{
A grande novidade do rádio na internet é o... áudio!
}

\section{The big novelty of internet radio is... audio!}

Eduardo Vicente ${ }^{1}$ 


\section{Resumo}

O artigo busca refletir sobre como nossa visão historicamente construída acerca do rádio pode estar dificultando uma discussão mais aprofundada das novas possibilidades expressivas e usos sociais do áudio, potencializados por práticas de produção e difusão contemporâneas como a do podcasting. Para tanto, o texto busca retomar as contribuições de teóricos que estudaram o veículo em diferentes momentos, com destaque especial para Arnheim (1936), Faus Belau (1973), Ortriwano (1985) e Cebrián Herreros (2001), com vistas a repensá-las criticamente no contexto atual. São ilustradas também algumas das possibilidades de uso da linguagem radiofônica exploradas atualmente, em especial, dentro do universo do podcasting.

\section{Palavras-chave}

Linguagem radiofônica, teoria do rádio, podcasting.

\section{Abstract}

The article seeks to reflect about how our historically constructed perspective on radio might be hindering a deeper discussion of the new expressive possibilities e social uses of radio enhanced by contemporary production and diffusion practices, such as podcasting. For such purpose, this article resume the contributions of theorists that studied this vehicle at different times, with special emphasis on Arnheim (1936), Faus Belau (1973), Ortriwano (1985) e Cebrián Herreros (2001), attempting to rethink them critically in the current context. Subsequently, some of the possibilities of using radio language explored nowadays are illustrated, especially within the podcasting universe.

\section{Keywords}

Radio language, radio theory, podcasting. 
A intenção deste artigo é refletir sobre o rádio atual a partir de uma perspectiva que privilegie sua linguagem e as possibilidades de uso social expressas, principalmente, através da prática do podcasting. Para tanto, num primeiro momento, o texto irá se debruçar sobre como nossa visão sobre o rádio, desde suas décadas iniciais, foi marcada pela questão da delimitação de seu lugar ou mesmo da probabilidade de sua morte - a partir do surgimento de novas mídias. Essa discussão pode nos ajudar a compreender como o lugar do rádio foi socialmente construído em diferentes momentos e, nesse sentido, em que medida concepções do passado podem estar moldando a forma pela qual o vemos atualmente. A seguir, serão elencadas algumas produções, principalmente do universo dos podcasts, que ilustram interessantes possibilidades de uso da linguagem radiofônica no contexto dessa bem-sucedida prática de difusão e consumo de conteúdos sonoros.

O ponto inicial dessa discussão é o livro Radio, do pesquisador alemão Rudolf Arnheim, publicado em 1936 sob o impacto do surgimento da televisão e do cinema sonoro. A seguir, é abordado o debate sobre o "lugar" do rádio diante de uma televisão que, desde os anos 1950, efetivamente se consolida. Isso é feito através das contribuições de Angel Faus Belau (1973) e Gisela Ortriwano (1985). Já no cenário contemporâneo, em que o rádio pode ser pensado a partir do contexto da internet e das mídias digitais, a aproximação maior será com a obra de Mariano Cebrián Herreros (2001). Em seguida, são apresentados exemplos de produções atuais que ilustram algumas das múltiplas possibilidades de utilização da linguagem sonora e radiofônica, bem como dos usos sociais que podem ser assumidos pelo rádio.

Uma importante razão para o desenvolvimento da reflexão histórica sobre o "lugar" do rádio aqui proposta é que, ainda que exista atualmente certo consenso em torno da definição do rádio enquanto linguagem mais do que como veículo, é preciso considerar que ele surge como resultado de uma invenção - um sistema de transmissão de áudio através de ondas eletromagnéticas - que, durante praticamente todo o século $X X$, foi basicamente seu espaço exclusivo de produção e veiculação. 
Assim, mesmo que nos últimos vinte anos novas práticas de produção e consumo tenham permitido um maior distanciamento entre o rádio enquanto linguagem e o rádio enquanto sistema técnico de transmissão de sinais, creio que é importante refletir sobre a forma pela qual as características de ambos acabaram por se confundir ao longo do tempo, podendo, às vezes, conduzir-nos a uma concepção limitadora do que é o rádio e, mais essencial ainda, do que ele pode ser.

\section{O referencial da cegueira de Rudolf Arnheim}

Ainda que Radio, de Rudolf Arnheim, publicado originalmente em 1936, seja certamente uma das obras pioneiras no estudo da linguagem radiofônica, no prefácio da reimpressão que marcou o $50^{\circ}$ aniversário de sua publicação, o autor afirma ter escrito o livro num momento em que considerava que o rádio, "a partir do desenvolvimento da televisão, seria em breve um capítulo encerrado do passado", e que foi sua "disposição conservacionista em preservar as realizações de artes em desaparecimento"2 (ARNHEIM, 1986, p. 7) que o levou a dedicar um olhar tão atento ao veículo.

Porém, como o autor também observa, seu prognóstico fora equivocado e

as décadas seguintes mostraram que som sem imagem e imagem sem som satisfaziam necessidades humanas tão básicas que eles não puderam ser simplesmente removidos quando a televisão e o filme sonoro dotaram os espetáculos populares de uma presença sensorial mais completa. (ARNHEIM, 1986, p. 7) 3

Ao analisar a "arte em desaparecimento" do rádio, Arnheim foca basicamente no que sua linguagem guarda de singular, ou seja, sua natureza puramente sonora. Mesmo constatando que "a preponderância sensorial do visual sobre o sonoro na 
nossa vida é tão grande que é muito difícil de se acostumar a considerar o mundo sonoro como mais do que apenas um complemento do mundo visual" (ARNHEIM, 1980, p. 85), o autor dedica um capítulo de seu livro justamente à celebração de uma arte sonora que prescinde da imagem, intitulando-o In praise of blindness: emancipation from the body ${ }^{4}$. Nessa reflexão, o autor aponta que os produtores deveriam valorizar o rádio por suas características próprias, isto é, como um meio cego, não incentivando a "criação" de imagens visuais por parte do ouvinte, pois isso "dificulta a compreensão da verdadeira essência do rádio, do que realmente nos enriquece e que só ele pode oferecer" (ARNHEIM, 1936, p. 137).

Arnheim nos traz vários exemplos desse uso, destacando a música, a voz do locutor e especialmente o radiodrama, que "apesar de seu caráter abstrato e irreal, é capaz de criar um mundo inteiro e completo em si mesmo com o material sensorial de que dispõe, atuando de maneira que não precise de nenhum complemento visual" (ARNHEIM, 1980, p. 86). Nesse percurso, o autor elenca diversas passagens da radiodramaturgia alemã dos anos 1920 e 1930 que não apenas ilustram a questão da "cegueira radiofônica" como atestam a extraordinária qualidade daquela produção.

A intenção, ao enfocar a obra de Arnheim nesse momento, é sublinhar o fato de que, para ele, é o desenvolvimento da linguagem radiofônica, daquilo que o rádio tem de absolutamente específico, que determina a sua posição - e, poderíamos acrescentar, sua sobrevivência - diante de mídias com uma "presença sensorial mais completa". De qualquer forma, como hoje sabemos, a televisão não só não estava prestes a substituir o rádio na década de 1930 como a chegada da guerra adiaria sua implantação por tempo significativo. Assim, as décadas de 1930 e 1940, nos Estados Unidos, e de 1940 e 1950, no Brasil, ainda foram as da Era do Ouro do rádio, marcada por um grande desenvolvimento da linguagem radiofônica através de programas de auditório, de variedades, musicais, ficcionais e jornalísticos, que se tornariam, inclusive, uma referência fundamental para o avanço posterior da 
televisão. De qualquer modo, sua consolidação tornaria incontornável a necessidade da rediscussão do lugar do rádio diante do novo cenário.

Abordaremos esse debate a partir das obras de dois autores: Angel Faus Belau (1973) e Gisela Ortriwano (1985). A escolha se deve, principalmente, ao fato de se tratarem de obras produzidas em países - Espanha e Brasil, respectivamente onde o rádio comercial, em sua relação com a televisão, certamente tinha feições muito diferentes daquelas assumidas onde o modelo predominante era público ou estatal. Outro ponto a aproximar esses autores - e, ao mesmo tempo, a distanciálos de Arnheim - é a sua formação jornalística e o forte papel que essa área de produção e estudos passaria a ocupar na tradição radiofônica dessas duas nações. Acima de tudo, ambos defenderam uma concepção de rádio que, ao menos no Brasil, iria se tornar hegemônica nas décadas seguintes.

\section{Rádio x televisão nas décadas de 1970 e 1980}

Em La radio: introducción a un medio desconocido (1973), Angel Faus Belau dedica considerável atenção à relação entre rádio e televisão. Para ele, o processo de expansão da televisão no mundo se dá, fundamentalmente, entre os anos de 1950 e 1965:

Costuma-se afirmar que a televisão desbancou o Rádio, assim como se dizia no início que acabaria com ele. Essa ideia, absurdamente generalizada, revela-se, desde nossa perspectiva atual, como totalmente carente de sentido [...]. Hoje cabe afirmar que o rádio vive e tem se renovado graças, precisamente, à televisão. (FAUS BELAU, 1973, p. 93) ${ }^{5}$

Para o autor, isso ocorre pelo fato de que, enquanto o rádio evoluiu, modificando completamente sua estrutura e fórmulas expressivas, a televisão passou a carregar, "desgraçadamente para ela, o fabuloso peso das massas", assimilando 
[...] fórmulas estruturadas para a comunicação sonora, que haviam se enrijecido e estavam em via de ser abandonadas. Assim, a televisão busca a tradução do rádio-espetáculo e integra em seu espaço o serial (telenovela), já bem aceito em geral, a produção dramática, os concursos (que por fidelidade ao seu ascendente radiofônico seguem sendo realizados diante do público, como no rádio dos anos 1940 e 1950), etc. De modo que o que tem sido habitualmente considerado uma crise não é senão uma reflexão criativa e organizadora, permitida pela televisão e muito condicionada pelas circunstâncias. (FAUS BELAU, 1973, p. 94)

Dentro da proposta (evidentemente elitista) do autor, o rádio, enfim "liberto" da produção seriada ficcional e de outros formatos de programação que caracterizaram sua Era do Ouro, passa a se orientar por dois eixos principais: a música e, principalmente, a produção noticiosa. Em ambos os casos, ele é favorecido, na visão de Belau, pela inovação tecnológica, especialmente a Frequência Modulada (FM), o transistor e a estereofonia (FAUS BELAU, 1973, p. 97), que possibilitariam tanto um grande desenvolvimento das emissoras locais quanto à melhoria da qualidade de transmissão/recepção e maior capacidade de ubiquidade do veículo (FAUS BELAU, 1973, p. 97-103).

No caso da música, o autor considera que, a partir da década de 1950, com a contribuição das inovações citadas acima e dos discos de microssulco, são superadas as limitações técnicas, econômicas e jurídicas do passado, o que permite a incorporação da música ao rádio como uma "parte muito importante de sua programação" (FAUS BELAU, 1973, p. 96) ${ }^{6}$.

De qualquer forma, para o autor, a "reflexão criativa" do rádio, a partir da chegada da televisão, "não se viu isenta de erros" (FAUS BELAU, 1973, p. 94) ${ }^{7}$. Voltando-se para o cenário dos Estados Unidos entre os anos de 1950 e 1955, ele aponta que a batalha do rádio se concentra no terreno informativo, ainda pouco desenvolvido na televisão, e as "unidades móveis saem à rua o de sua capitulação enquanto espaço de produção musical, com o fim da tradição (ao menos no Brasil) das orquestras próprias e intérpretes contratados. 
em busca da notícia viva, direta, 'quente'" (FAUS BELAU, 1973, p. 94-95)83. Mas há um porém:

\begin{abstract}
Conforme avança a década e se acumula a experiência, percebe-se também que o rádio não pode ser apenas um instrumento de informação fugaz, mas que é necessário oferecer ao ouvinte os dados necessários para que as mensagens sirvam também como um princípio de reflexão. Nesse sentido, surgem os programas informativos de profundidade e análise. (FAUS BELAU, 1973, p. 95) ${ }^{9}$
\end{abstract}

Por conta disso, Faus Belau entende que o desenvolvimento do rádio na Europa, entre 1965 e 1973, período mais recente de sua análise, será baseado justamente nessa informação em profundidade e na presença da emissora local ${ }^{10}$. Ele também destaca que "a radiodifusão europeia segue mantendo um interesse especial pelas obras dramáticas" (FAUS BELAU, 1973, p. 107)11. Mas trata-se, nesse caso, de "autênticas obras de cultura", distantes da ficção seriada massiva de décadas anteriores.

Escrevendo em período um pouco posterior (1985), mas igualmente a partir da perspectiva do jornalismo, Gisela Ortriwano vai tratar, em sua discussão sobre o rádio no Brasil, de questões muito próximas daquelas abordadas por Angel Faus Belau. Ao discutir a relação entre rádio e televisão, a autora aponta uma crise advinda da perda de quadros (técnicos e artísticos) e da verba publicitária, na qual,

para enfrentar a concorrência da televisão, o rádio precisava procurar uma nova linguagem, mais econômica. [...] aprendeu a trocar os astros e estrelas por discos e fitas gravadas, as novelas pelas notícias e as brincadeiras de auditório pelos serviços de utilidade pública. Foi-se encaminhando no

Do original: "Unidades móviles salen a la calle en busca de la noticia viva, directa y 'caliente"".

Do original: "Conforme avanza la década y se acumula la experiencia, se piensa también en que la Radio no sólo puede ser un instrumento de información fugaz, sino que es necesario facilitar al oyente los datos necesarios para que los mensajes sirvan también como un principio de meditación. En este sentido, se comienzan los programas informativos en profundidad y análisis". 
sentido de atender às necessidades regionais, principalmente ao nível da informação. [...] das produções caras, com multidões de contratados, o rádio parte agora para uma comunicação ágil, noticiosa e de serviços". (ORTRIWANO, 1985, p. 21-22)

Nesses "novos rumos", ditados também pelo transistor, pelas emissoras de FM e pela emergência das redes, temos ainda a valorização do rádio ao vivo, que pode transmitir o "instante que passa" (ORTRIWANO, 1985, p. 31) e que está implícito em características apontadas pela autora para o veículo, como a "mobilidade do emissor" e o "imediatismo", com transmissão dos fatos em tempo real (ORTRIWANO, 1985, p. 78). Além dessas, a autora elenca outras características do rádio (ORTRIWANO, 1985, p. 78-81) entre as quais destacaria sua "instantaneidade", ou seja, o fato da mensagem existir apenas durante o momento da transmissão, obrigando à recepção imediata ${ }^{12}$.

Na conclusão de Ortriwano, "o rádio não morreu quando surgiu a televisão, apesar da perplexidade inicial diante do aparecimento de outro meio tecnologicamente mais sofisticado: primeiro, se acomodou, mas, depois, se especializou em sua própria faixa de potencialidade" (ORTRIWANO, 1985, p. 81). Nesses termos, pode-se afirmar que sua visão coincide com a de Faus Belau. Nas contribuições de ambos, chama a atenção especialmente a perspectiva, em certa medida, evolucionista e naturalizante da trajetória do rádio, na qual as mudanças do veículo diante da televisão não são vistas como limitadoras, mas como o caminho pelo qual o rádio se liberta de "fórmulas enrijecidas" e encontra seu "novo rumo", sua "faixa de potencialidade".

Nesses relatos, em que o rádio surge como uma espécie de protagonista de sua própria história, tornam-se menos evidentes questões fundamentais para um debate acerca de outros caminhos possíveis. Em primeiro lugar, seria preciso considerar que os cenários apontados pelos autores correspondem, como vimos, ao modelo comercial de radiodifusão, desconsiderando a dinâmica assumida pelo veículo em modelos predominantemente públicos ou estatais - caso de 
vários países europeus no momento em que os autores publicaram seus textos. Em segundo, a visão do rádio enquanto espaço de produção vinculado de forma praticamente exclusiva ao jornalismo é assumida como evolução natural, e não enquanto uma limitação de seu escopo de atuação. Por fim, diferentemente do que ocorre na discussão desenvolvida por Arnheim, não temos, em nenhum dos relatos, um debate mais voltado à análise de obras: o papel central é do veículo, das emissoras, de sua base tecnológica, e não da linguagem desenvolvida ou dos programas de destaque.

É bastante compreensível, pela sua própria formação, a ênfase dos autores no jornalismo radiofônico. E considerando-se a então necessidade de situar o rádio diante de uma televisão em rápida expansão, também o foco era no quadro mais imediato. Porém, a partir de uma perspectiva histórica, é preciso reconhecer que, ao descartarem como elementos de um passado já superado significativa parcela da diversidade de produção desenvolvida em períodos anteriores, os autores acabaram por desconsiderar a possibilidade de uma renovação da linguagem radiofônica e, através dela, de uma atualização de gêneros e formatos.

Entende-se que o podcasting, para falarmos em apenas uma das práticas de produção radiofônica do cenário atual, mostra que retomar a perspectiva do rádio enquanto linguagem - situando a veiculação musical e os formatos tradicionais do radiojornalismo de Faus Belau e Ortriwano como resultados de condições específicas e historicamente situadas de produção da modalidade terrestre, e não de uma "evolução" do rádio enquanto linguagem - é um exercício fundamental para que se possa assumir um olhar renovado sobre as múltiplas potencialidades da linguagem radiofônica e de seus possíveis usos sociais na atualidade. Inclusive no sentido de uma renovação do debate sobre a produção do próprio radiojornalismo.

Por essa razão, será desenvolvida adiante uma reflexão mais atual sobre o lugar do rádio que tem como "outro" o contexto da internet e das mídias digitais. Para essa discussão, abordarei a obra de Cebrián Herreros. Essa escolha devese tanto ao fato de se tratar de uma reflexão desenvolvida num momento ainda 
bastante inicial da relação entre rádio e internet - o que Ihe dá um significativo frescor e a aproxima, num certo sentido, da contribuição de Arnheim - como ao distanciamento do autor em relação ao jornalismo ${ }^{13}$, o que nos permitirá, acredito, contrabalancear o debate anterior.

\section{Rádio e internet}

Se a discussão sobre o rádio frente à televisão teve o que apontamos como um caráter mais limitador nos anos 1970-1980, diante do advento das tecnologias digitais e da internet, ela ganhou outros contornos. Cebrián Herreros, escrevendo em 2001, afirmou de forma categórica: "Assistimos a uma mudança tecnológica transcendental no rádio, mais importante ainda do que a que ele viveu com a incorporação dos transistores, da FM e da estereofonia" (2001, p. 20) ${ }^{14}$. E agora,

não se trata tanto de rádio por Internet e sim de informação sonora que pode ser vinculada a elementos gráficos e visuais, de ruptura do sincronismo que deixa o usuário livre temporal e espacialmente para que retorne quando quiser. $O$ rádio por internet é diferente do rádio. Será preciso buscar para ele uma denominação mais precisa. (CEBRIÁN HERREROS, 2001, p. 21) ${ }^{15}$

O autor vê nesse rádio "diferente" a "capacidade interativa e, consequentemente, a possibilidade de uma mudança no modelo comunicativo do rádio" (CEBRIÁN HERREROS, 2001, p. 27) ${ }^{16}$. Mas ele também avisa: "O rádio do futuro, por mais inovações técnicas que tenha, continuará se baseando na comunicação oral com a audiência, na magia da palavra, das ambientações sonoras, do silêncio" (CEBRIÁN temporal y espacialmente para que acuda cuando quiera. La radio por Internet es otra cosa diferente a la radio. Habrá que buscar una denominación más precisa". 
HERREROS, 2001, p. 32) ${ }^{17}$. Com isso, Cebrián Herreros se aproxima da posição de Arnheim em relação à economia da linguagem radiofônica e à importância da valorização do que lhe é singular. Em reforço a essa posição, o autor ressalta a ligação entre o rádio e a tradição oral, da qual seria o grande amplificador e atualizador (CEBRIÁN HERREROS, 2001, p. 32). Por conta disso, imagem e texto aparecerão nas produções radiofônicas "como um complemento e nunca como substituição ou com maior relevância" (CEBRIÁN HERREROS, 2001, p. 220)18.

No que tange à audiência, ele aponta que "todo o desenvolvimento discutido da Internet como dos demais sistemas de difusão traz consigo uma clara fragmentação da audiência" e, como consequência, surge a possibilidade de um rádio personalizado em um duplo sentido:

Se faz personalizado quando cada ouvinte pode escolher o canal ou o programa que deseje tanto na difusão ao vivo como nas gravações de emissões anteriores [...]. O segundo sentido do rádio personalizado nasce da possibilidade da criação de mensagens por cada usuário. (CEBRIÁN HERREROS, 2001, p. 119-120) $)^{19}$

Temos, assim,

[...] a passagem do rádio massivo ao rádio de uso pessoal. É uma mudança na concepção do meio, é um rádio novo e diferente cujo desenvolvimento requer outros conteúdos mais permanentes ou atualizações contínuas e tratamentos de acordo com uma informação armazenada e reescutável. (CEBRIÁN HERREROS, 2001, p. 218)20

Do original: "La radio del futuro, por más innovaciones técnicas que introduzca, seguirá basándose en la comunicación oral con la audiencia, en la magia de la palabra, de la música, de los sonidos de ambiente, del silencio".

Do original: "Todo el desarrollo indicado de Internet como el de los demás sistemas de difusión lo que trae consigo es una manifiesta fragmentación de audiencia". "Se hace personalizada cuando cada oyente puede elegir el canal, el programa que desee tanto en la difusión en directo como en las grabaciones de emisiones anteriores [...]. El segundo sentido de radio personalizada procede de la posibilidad de creación de mensajes por cada usuario". una radio nueva y diferente cuyo desarrollo requiere otros contenidos más permanentes o actualizaciones continuas y tratamientos acordes con la información almacenada $Y$ reescuchable. La radio de masas tradicional difunde para núcleos amplios de población de manera simultánea. La radio individual permite la selección por parte de cada usuario". 
A associação da ideia de uma audiência fragmentada e de uma produção/ recepção mais individualizada à perspectiva de um rádio mais interativo surge como uma das proposições mais instigantes do texto, que, nesse sentido, recupera o ideal brechtiano da rebelião do ouvinte e de "sua ativação e sua reabilitação como produtor" (BRECHT, 2005, p. 39). A ideia também nos permite superar a mera oposição entre consumo restrito e ampliado como determinantes do que seria um rádio "elitista" ou "popular", com todas as conotações problemáticas implicadas nesses termos ${ }^{21}$. Em lugar disso, a proposição de Cebrián Herreros nos convida a refletir sobre uma produção que passa a ser determinada muito mais pelas demandas identitárias ou de grupos de interesse do que pela proximidade geográfica e escassez de canais que caracterizam as transmissões radiofônicas convencionais.

O autor também discute as diferenças entre esse "novo rádio" e o tradicional a partir de suas características. As questões do imediatismo e da instantaneidade, relidas através da oposição entre sincronia e assincronia, são centrais em sua reflexão:

O rádio tradicional tem como ponto forte ou ponto fraco, depende de como se considere, o sincronismo que estabelece entre a emissão e a recepção. O ponto forte se baseia na imediatez, na capacidade da transmissão direta dos acontecimentos. [...] O ponto fraco aparece na fugacidade da mensagem, que se baseia no transcurso do tempo, e na debilidade da memória auditiva do ouvinte.

No sistema assíncrono, pelo contrário, a situação é modificada. A informação é armazenada. A fugacidade é destruída e se permite ao ouvinte recuperar a informação quando desejar. (CEBRIÁN HERREROS, 2001, p. 217) 22

Em textos posteriores, ele retornará a esse tema considerando já a existência de audioblogs, podcasts e outros produtos da presença do rádio na internet (CEBRIÁN autorais no cenário radiofônico paulistano (São Paulo: ECA/USP, 2015). Disponível em: https://bit.ly/2QozuEG. Acesso em: 29 jun. 2021. la transmisión en directo de los acontecimientos. [...] El punto débil aparece en la fugacidad del mensaje debido a que se basa en el transcurso del tiempo y en la debilidad de la memoria auditiva del oyente. En el sistema asincrónico, por el contrario, se modifica la situación. La información se almacena. Se destruye la fugacidad y se deja capacidad al oyente para que recupere la información cuando lo desee". 
HERREROS, 2007, p. 104), mas esses novos trabalhos pouco acrescentam às ideias que nos interessam aqui. Para as intenções deste texto, gostaria de reter a reflexão de Cebrián Herreros, principalmente a ideia de uma ampliação do escopo de atuação do rádio, à proposição acerca da possibilidade de um rádio de uso pessoal e o conceito de assincronia. Entendo que esses elementos são fundamentais numa discussão sobre a prática do podcasting e de outras modalidades de produção e distribuição digital de áudio, recolocando de forma bastante intensa a importância da linguagem radiofônica e da diversidade de formatos.

\section{De volta à linguagem radiofônica}

Em relação à ideia da fragmentação da audiência, vinculada ao que Cebrián Herreros define como um "rádio pessoal", o podcasting tem permitido a criação de programas que, superada a limitação geográfica das transmissões, podem se dirigir a um público agora delineado a partir de demandas identitárias e interesses específicos (culturais, sociais, políticos, ambientais). Entre os muitos exemplos de produções brasileiras que assumem tal proposta, podemos citar Originárias ${ }^{23}$, programa lançado em 2019 pela Rádio Yandê e dedicado a difundir o trabalho de artistas e músicos indígenas; Feito por Elas ${ }^{24}$, podcast feminista em que as apresentadoras analisam filmes dirigidos por mulheres; data_lábia ${ }^{25}$, produzido pelo data_labe, um laboratório de dados e narrativas da favela da Maré, no Rio de Janeiro; e ReversaCast ${ }^{26}$, produção voltada ao universo e ao público LGBT+, entre outros.

Nesse mesmo sentido, diferentes militâncias, além do jornalismo alternativo, têm encontrado na prática do podcasting um importante espaço de expressão. Ainda dentro do cenário nacional, podem ser citadas produções como As Árvores

Disponível em: https://apple.co/3bxFeDz.

Disponível em: https://bit.ly/3hyl4NG.

Disponível em: https://bit.ly/3ftsZZK. 
Somos Nozes ${ }^{27}$, podcast sobre questões ambientais criado pelo Greenpeace Brasil; Mamilos $^{28}$, programa de entrevistas que busca abordar questões da atualidade; Durma com essa ${ }^{29}$, podcast de notícias do jornal digital Nexo; Foro de Teresina ${ }^{30}$, produção semanal sobre política vinculada à Revista Piauí; Xadrez Verbal¹, programa de produção independente com debates sobre política internacional; e Guilhotina32, podcast de entrevistas do jornal Le Monde Diplomatique Brasil.

Em relação a um uso mais original das tecnologias e da linguagem sonora, destacam-se produções que se valem do recurso da binauralidade. O termo se refere a uma possibilidade de escuta subjetiva, simulando um ambiente sonoro tridimensional, que pode ser eficientemente reproduzido através de fones de ouvido convencionais. Esse resultado é obtido a partir do uso de microfones especiais para a captação de som.

Embora o Théâtrophone, sistema de transmissão de áudio criado em 1881 pelo engenheiro francês Clément Ader (CROOK, 1999, p. 15), já buscasse simular o efeito, apenas em anos recentes gravações binaurais efetivamente chegaram a um público amplo. Seu uso se tornou mais popular tanto em função das facilidades tecnológicas existentes quanto do reforço do hábito da escuta por meio de fones de ouvido implicados no uso de smartphones e tablets. No rádio ficcional, por exemplo, suas possibilidades foram exploradas em produções como Virtual Barber Shop (1996) e Dark House (2002)33. Mas o destaque que o áudio

Disponível em: https://bit.ly/3fthzFk.

Disponível em: https://bit.ly/3hylIKX.

Disponível em: https://bit.ly/33QALHR.

Disponível em: https://bit.ly/3yiezV1.

Disponível em: https://bit.ly/2T1rz1j.

Disponível em: https://bit.ly/3eS7uCL.

Virtual Barber Shop coloca o ouvinte na condição de cliente de um salão de cabeleireiros. Criada pelo QSound Labs, a peça tem aproximadamente cinco minutos de duração e foi disponibilizada no YouTube em 2008. A versão mais acessada (disponível em: https://bit.ly/3uRtBim) contava, no primeiro semestre de 2021, com mais de 36 milhões de reproduções. Já Dark House (disponível em: https://bbc.in/3foFt4P) foi criada em 2002 por Izzy Mant e Nick Ryan em colaboração com a BBC. Trata-se de uma história de suspense (não mais disponível na internet) na qual os ouvintes têm a oportunidade de escolher a partir da perspectiva de qual dos três personagens da trama gostariam de ouvir cada trecho da obra. 
binaural recebe aqui refere-se ao fato de ter se tornado a base de toda uma nova modalidade de consumo sonoro denominada Autonomous Sensory Meridian Response (ASMR) ou, em português, Resposta Sensorial Meridiana Autônoma. A ASMR, definida como "uma agradável sensação de relaxamento que pode ser acompanhada por um formigamento que vai da cabeça até o final da coluna" (RUBIO; SANCHIS; RIVAS, 2018), seria provocada pela audição de gravações binaurais de diferentes sons.

As opções disponíveis passam pelos sons de animais domésticos, de objetos como tesouras, pentes e secadores de cabelo, por diversos sons da natureza, instrumentos musicais, gemidos sensuais, entre dezenas de outras possibilidades. A ASMR é distribuída principalmente na forma de vídeos disponibilizados no YouTube, inclusive com transmissões ao vivo. As produções são feitas predominantemente por mulheres e somam por volta de 500 vídeos diários (KEILES, 2019). Mas o que esses vídeos de um modo geral trazem é a performance da(o) responsável pelo canal diante de um microfone binaural ${ }^{34}$.

Também o jornalismo radiofônico, valorizado como vimos nas reflexões de Ortriwano e Faus Belau, tem ganhado importante destaque no contexto atual. Além da imprensa alternativa, veículos tradicionais como The New York Times ${ }^{35}$, The Guardian ${ }^{36}$, El País ${ }^{37}$ e Folha de S.Paulo ${ }^{38}$, entre outros, estão produzindo podcasts como canais adicionais de informação e fidelização de seus ouvintes. Mas um fator ainda mais significativo em relação à renovação do gênero é o surgimento de importantes podcasts jornalísticos com produções bastante sofisticadas e de caráter fortemente autoral, próximos da tradição do jornalismo narrativo ${ }^{39}$.

Recomendo, por exemplo, o canal ASMR (disponível em: https://bit.ly/3tSOIVO), que traz performances ao vivo.

Disponível em: https://nyti.ms/3bB9Tjs.

Disponível em: https://bit.ly/2QsOBx2.

Disponível em: https://bit.ly/2SSIS5r.

Disponível em: https://bit.ly/3ooMCGm.

A aproximação entre jornalismo narrativo e reportagens radiofônicas criativas já tinha sido apontada por Nivaldo Ferraz (2016). 
Produções premiadas como This American Life ${ }^{40}$, lançada em 1995 pela National Public Radio (NPR) norte-americana e distribuída posteriormente como podcast; Serial ${ }^{41}$, um spin-off de This American Life produzido por Sarah Koenig em 2014 que se tornou o mais importante podcast criado até aquele momento; Radio Ambulante ${ }^{42}$, criado em 2011 por Daniel Alarcón com narrativas de todos os países de fala espanhola da América Latina; ou ainda o espanhol Le Llamaban Padre $^{43}$, adaptação de José Ángel Esteban do livro homônimo de Carles Porta, demonstram a força dessa tradição.

Como elementos comuns, esses podcasts se utilizam de músicas, ambientes e efeitos sonoros de forma sistemática e, principalmente, adotam um intenso trabalho de roteirização e edição que se aproxima das práticas de produção de documentários audiovisuais. Assim, o imediatismo e a instantaneidade são substituídos por um trabalho de cuidadosa elaboração, pela profundidade da investigação e por um investimento mais autoral dos realizadores na construção de suas narrativas e personagens ${ }^{44}$.

A produção radiofônica ficcional seriada, por sua vez, representa um fenômeno mais recente e, no meu entender, ainda pouco representativa no universo dos podcasts. Porém, já podem ser encontrados trabalhos que se utilizam de forma bem interessante do gênero, como as produções espanholas Bienvenido a la vida peligrosa ${ }^{45}$ e El gran apagón ${ }^{46}$. A primeira, escrita por Arturo Pérez-Reverte e dirigida por Guillermo Arriaga, narra as aventuras de um professor espanhol

Disponível em: https://bit.ly/3uXpBge.

Disponível em: https://bit.ly/2SYXD5O.

Disponível em: https://bit.ly/3uX5m2q

Disponível em: https://bit.ly/2QsNhdy.

Em sua pesquisa de pós-doutorado, o documentário no rádio: desenvolvimento histórico e tendências atuais (São Paulo: ECA/USP, 2018), Márcia Detoni oferece uma discussão mais detalhada sobre essa tradição de produções e a forma pela qual elas empregam as técnicas de storytelling.

Disponível em: https://bit.ly/2SXoDCJ.

Disponível em: https://bit.ly/2RhPNDZ. 
de filosofia que se envolve involuntariamente com narcotraficantes no México. A segunda, com roteiro de Jose Pérez Ledo e direção de Ana Alonso, assume o formato de um documentário para mostrar as consequências de uma gigantesca tempestade solar que derruba as redes elétricas e os sistemas de comunicação do planeta. Ambas as produções contam com atores já conhecidos na Espanha por seus trabalhos no cinema e na televisão.

O mesmo ocorre em Homecoming ${ }^{47}$, podcast de 2017 da produtora norteamericana Gimlet Media, estrelado por Catherine Keener, Oscar Isaac, David Schwimmer, Amy Sedaris e David Cross. Na série, a trama gira em torno de um projeto de readaptação de veteranos de guerra norte-americanos que retornam ao seu país. Em todas essas produções temos um sofisticado trabalho de direção e edição, com mudanças de ambientes e criativa utilização de efeitos e música para a construção das narrativas. Muito mais próximas do referencial atual das séries em vídeo de plataformas como Netflix ou Amazon Prime do que propriamente da ideia de meio cego de Arnheim. Elas implicam um investimento e esforço de renovação de uma produção ficcional serializada que, como vimos, representava para Faus Belau um passado já superado do rádio.

Há também podcasts ligados a projetos intermidiáticos, que surgem, por exemplo, como produções derivadas de séries em vídeo. Blue Planet II: The Podcast ${ }^{48}$, da BBC 1, traz o making of e uma discussão complementar de questões ambientais apresentadas na série televisiva de mesmo nome. Já a série La Peste, veiculada em 2017 pela emissora espanhola Movistar+, trazia dois podcasts dentro do seu "Universo Transmedia"49: em El Confesor, eram apresentadas versões estendidas das confissões de personagens da série ao Tribunal da Santa Inquisição. Los Inquisidores, por sua vez, trazia comentários dos criadores da série e entrevistas com o elenco e

\footnotetext{
47 Disponível em: https://bit.ly/3oq4dOv.

48 Disponível em: https://bbc.in/3tSOwQH. 
com os membros da equipe de produção. Já no podcast Song Exploder ${ }^{50}$, a relação intermidiática mais forte é com o mundo da música, uma vez que a série traz, a cada episódio, uma entrevista com um(a) artista musical explicando o processo de criação e gravação de uma canção, que é decomposta em seus diversos elementos e trilhas instrumentais ao longo da narração.

Vale ressaltar que, em todos esses casos, as produções mantêm sua autonomia enquanto obras sonoras baseadas, como aponta Cebrián Herreros, "na comunicação oral com a audiência, na magia da palavra, da música, das ambientações sonoras, do silêncio" (2001, p. 32). Mas acreditamos que a mais importante demonstração da força da linguagem sonora, atualmente, vem de experiências transmidiáticas representadas pela adaptação de podcasts na forma de séries televisivas.

O podcast Lore ${ }^{51}$, por exemplo, criado em 2015 por Aaron Mahnke e que usa exclusivamente a voz de seu apresentador e um fundo musical para trazer relatos sobre fatos estranhos ocorridos no passado, foi adaptado como série de vídeo pela Amazon Prime em 2017, através de episódios que reúnem animação, dramatizações, imagens de arquivo e narração do autor. A série televisiva já recebeu uma segunda temporada. Homecoming, a já citada produção ficcional da Gimlet Media, foi adaptada em 2018 também pela Amazon Prime, com direção de Sam Esmail e com Julia Roberts como protagonista.

Já Dirty John52, o podcast jornalístico criado por Christopher Goffard em 2017 que narra a trajetória criminal de John Meehan, foi a base para a criação tanto da série documental Dirty John: the dirty truth, de 2019, da Netflix, como da dramatização em vídeo da história produzida um ano antes pela produtora Bravo $^{53}$. A primeira temporada do já citado podcast Serial, de 2014, ganhou uma 
adaptação da HBO (BROWNING, 2018)54, enquanto a versão em vídeo de Song Exploder está disponível na Netflix ${ }^{55}$.

\section{Considerações finais}

A intenção deste texto foi demonstrar que a visão dominante sobre o rádio tendeu a mudar através do tempo, especialmente a partir do seu reposicionamento diante do surgimento de novas mídias. Por conta disso, ela pode ainda ser marcada por noções historicamente construídas, não mais válidas num cenário caracterizado pela expansão das possibilidades de produção e difusão oferecidas pelas tecnologias digitais e pela internet. A partir dessa perspectiva, demonstrou-se que discussões mais ligadas à linguagem e ao potencial do rádio, como a empreendida por Rudolf Arnheim, em 1936, e, mais recentemente, por Cebrián Herreros, podem nos auxiliar na construção de uma visão mais ampla sobre as possibilidades expressivas e sociais do rádio em seu novo contexto digital.

Para ilustrar esse quadro, foram inclusos no texto diversos exemplos de produções sonoras contemporâneas, visando elucidar algumas das tendências e possíveis usos da linguagem radiofônica, especialmente em programas veiculados através do streaming. Nesse sentido, buscou-se uma aproximação, para a discussão sobre o rádio, da proposta que Arlindo Machado faz para o estudo da televisão, ou seja, pensar o veículo também a partir da perspectiva do repertório desenvolvido e da análise de obras que, de alguma maneira, se destacaram "da massa amorfa da trivialidade" (MACHADO, 2000, p. 19).

Dentro dos limites do artigo, não foi possível oferecer uma análise mais elaborada das obras e tendências citadas e nem empreender uma discussão mais detalhada de sua linguagem. Porém, destacamos aqui a importância desse tipo de abordagem e o fato de que ela implica enfrentar o desafio que Murray Schafer 
propõe ao afirmar que, ao contrário da poesia e da pintura, o rádio não possui um "aparato exegético" que permita sua definição enquanto uma forma de arte (SCHAFER, 1997, p. 33).

Nesses termos, uma análise mais minuciosa de obras radiofônicas complexas certamente requer o desenvolvimento e a utilização de um instrumental teórico que vá além da mera enumeração dos elementos da linguagem sonora - música, voz, ruído e silêncio - a que tradicionalmente nos limitamos. Tentei abordar essa questão em trabalho anterior, em que inclusive proponho uma aproximação a autores mais ligados ao estudo da trilha sonora cinematográfica, especialmente Michel Chion e Claudia Gorbman ${ }^{56}$. Um mergulho mais profundo na discussão da linguagem sonora utilizada em diversas produções atuais nos permitirá superar amplamente a ideia de que sua originalidade se resume ao fato de incorporarem elementos visuais. Constatação que, certamente, não explica o imenso interesse que elas têm despertado e muito menos o fato de diversas delas estarem sendo adaptadas para o vídeo.

Assim, espero que o conjunto de reflexões aqui apresentado, bem como a breve ilustração do cenário radiofônico atual que o texto busca oferecer, ajude a esclarecer e defender a afirmação contida no título: a de que, para além das possibilidades inter e transmidiáticas, ou dos elementos visuais, textuais e gráficos que possam ser agregados às produções, a grande novidade, magia e força do rádio na internet é, acima de tudo, o áudio.

\section{Referências}

ARNHEIM, R. Radio. Salem: Ayer Co., 1986.

BRECHT, B. Teoria do rádio (1927-1932). In: Meditsch, E. (org.). Teorias do rádio: textos e contextos. Florianópolis: Insular, 2005. v. 1, p. 35-45. 
BROWNING, J. From Homecoming to Dirty John, 10 podcasts that have inspired TV shows. Enterteinment Weekly, Los Angeles, 4 out. 2018. Disponível em: https://bit.ly/3fiH8ZC. Acesso em: 20 set. 2019.

CEBRIÁN HERREROS, M. La radio en la convergencia multimedia. Barcelona: Gedisa, 2001.

CEBRIÁN HERREROS, M. Modelos de radio, desarollos y innovación: Del diálogo y paticipación a la interactividad. Madri: Fragua, 2007.

CROOK, T. Radio drama: theory and practice. Londres: Routledge, 1999.

FAUS BELAU, A. La radio: introducción a un medio desconocido. Madri: Guadiana de Publicaciones, 1973.

FERRAZ, N. Reportagem no rádio: realidade brasileira, fundamentação, possibilidades sonoras e jornalísticas a partir da peça radiofônica reportagem. 2016. Tese (Doutorado em Meios e Processos Audiovisuais) - Escola de Comunicações e Artes, Universidade de São Paulo, São Paulo, 2016.

GIANNINI, A. Caso Evandro, podcast que virou febre com investigação de crime, vai virar série e livro. O Globo, Rio de Janeiro, 4 jun. 2019. Disponível em: https://glo.bo/3hxquZ3. Acesso em: 12 nov. 2019.

KEILES, J. L. How A.S.M.R. became a sensation. The New York Times Magazine, Nova Iorque, 4 abr. 2019. Disponível em: https://nyti.ms/2RiEz24. Acesso em: 22 set. 2019.

MACHADO, A. A televisão levada a sério. São Paulo: Editora Senac, 2000. 
ORTRIWANO, G. A informação no rádio: os grupos de poder e a determinação dos conteúdos. 5. ed. São Paulo: Summus, 1985.

RUBIO, I.; SANCHIS, A.; RIVAS, L. M. O mistério dos sussurros que são um sucesso no YouTube. El País Brasil, São Paulo, 18 abr. 2018. Disponível em: https://bit. ly/33PyGvA. Acesso em: 22 set. 2020.

SCHAFER, M. R. Rádio radical. In: ZAREMBA, L; BENTES, I. (org.). Rádio nova: constelações da radiofonia contemporânea. v. 2. Rio de Janeiro: ECO, 1997. p. 27-40.

submetido em: 26 mar. 2021 | aprovado em: 21 abr. 2021 